\title{
Substituting dietary saturated for monounsaturated fat impairs insulin sensitivity in healthy men and women: The KANWU study
}

\author{
B. Vessby ${ }^{1}$, M. Uusitupa ${ }^{2}$, K.Hermansen ${ }^{3}$, G. Riccardi ${ }^{4}$, A. A. Rivellese ${ }^{4}$, L. C. Tapsell ${ }^{5}$, C. Nälsén ${ }^{1}$, L. Berglund ${ }^{1}$,

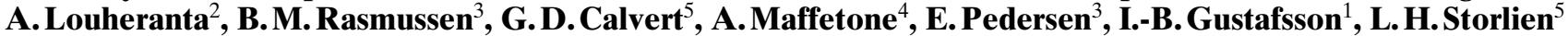 \\ ${ }^{1}$ Unit for Clinical Nutrition Research, Department of Public Health and Caring Sciences/Geriatrics, University of Uppsala, \\ Uppsala, Sweden \\ ${ }^{2}$ Department of Clinical Nutrition, University of Kuopio, Kuopio, Finland \\ ${ }^{3}$ Department of Clinical Endocrinology and Metabolism, Aarhus Amtssygehus and Aarhus University, Aarhus, Denmark \\ ${ }^{4}$ Department of Clinical and Experimental Medicine, School of Medicine, Federico II University, Naples, Italy \\ ${ }^{5}$ Department of Biomedical Sciences and Medical Research Unit, University of Wollongong, Wollongong, Australia
}

\section{Abstract}

Aims/hypothesis. The amount and quality of fat in the diet could be of importance for development of insulin resistance and related metabolic disorders. Our aim was to determine whether a change in dietary fat quality alone could alter insulin action in humans. Methods. The KANWU study included 162 healthy subjects chosen at random to receive a controlled, isoenergetic diet for 3 months containing either a high proportion of saturated (SAFA diet) or monounsaturated (MUFA diet) fatty acids. Within each group there was a second assignment at random to supplements with fish oil (3.6 g n-3 fatty acids/d) or placebo. Results. Insulin sensitivity was significantly impaired on the saturated fatty acid diet $(-10 \%, p=0.03)$ but did not change on the monounsaturated fatty acid diet $(+2 \%, \mathrm{NS})(p=0.05$ for difference between diets $)$. Insulin secretion was not affected. The addition of $n-3$ fatty acids influenced neither insulin sensitivity nor insulin secretion. The favourable effects of substituting a monounsaturated fatty acid diet for a saturated fatty acid diet on insulin sensitivity were only seen at a total fat intake below median (37E \%). Here, insulin sensitivity was $12.5 \%$ lower and $8.8 \%$ higher on the saturated fatty acid diet and monounsaturated fatty acid diet respectively $(p=0.03)$. Low density lipoprotein cholesterol (LDL) increased on the saturated fatty acid $\operatorname{diet}(+4.1 \%, p<0.01)$ but decreased on the monounsaturated fatty acid diet (MUFA) $(-5.2, p<0.001)$, whereas lipoprotein (a) $[\mathrm{Lp}(\mathrm{a})]$ increased on a monounsaturated fatty acid diet by $12 \%(p<0.001)$.

Conclusions/interpretation. A change of the proportions of dietary fatty acids, decreasing saturated fatty acid and increasing monounsaturated fatty acid, improves insulin sensitivity but has no effect on insulin secretion. A beneficial impact of the fat quality on insulin sensitivity is not seen in individuals with a high fat intake ( > 37E \%). [Diabetologia (2001) 44: 312319]

Keywords Diet, saturated fatty acids, monounsaturated fatty acids, n-3 fatty acids, insulin sensitivity, insulin secretion, serum lipoproteins.
Insulin resistance is central for the aetiology of the metabolic syndrome cluster of disease: blood lipid

Received: 21 August 2000 and in revised form: 8 November 2000

Corresponding author: B. Vessby, M. D., Department of Public Health and Caring Sciences/Geriatrics, University of Uppsala, PO Box 609, SE75125 Uppsala, Sweden

Abbreviations: E \%, Energy percent; MUFA, monounsaturated fatty acids; PUFA, polyunsaturated fatty acids; SAFA, saturated fatty acids; $\mathrm{SD}$, standard deviation; $\mathrm{Si}$, insulin sensivity index; LDL, low density lipoprotein; Apo, apolipoprotein; Lp(a), lipoprotein(a). disorders, hypertension, propensity for thrombus formation, abdominal obesity and Type II (insulin-dependent) diabetes mellitus [1]. Although genetic predisposition is a factor, the prevalence of obesity and diabetes is increasing rapidly in both developed and developing countries [2] arguing that lifestyle factors such as dietary and physical activity patterns, which are amenable to change, modulate insulin action and hence disease development.

Experimental and clinical data suggest that the amount and quality of fat in the diet could be important for the development of insulin resistance and related metabolic disorders [3]. A high proportion of 
long-chain unsaturated fatty acids and a low proportion of saturated fatty acids in the phospholipids of the skeletal muscle membranes have been related to a high insulin sensitivity in humans with or without coronary heart disease [4-6]. There have also been suggestions that dietary fat quality affects glucose stimulated insulin secretion [7-9].

Although experimental studies [3], as well as cross-sectional and prospective studies in humans [3, $10]$, indicate that fat quality could influence insulin sensitivity, this has not been shown in intervention studies in humans. Due to the complex nature of controlled dietary trials, most intervention studies have had a limited number of subjects and been of short duration.

Our aim was to carry out a study of adequate size and duration to examine whether a change of dietary fat quality affects insulin sensitivity in humans. The effects of a diet with a high proportion of saturated fatty acids were compared with those of a diet with the same total fat content but with a high proportion of monounsaturated fatty acids. Our secondary aim was to investigate the possible effects of a change of fat quality on glucose-induced insulin secretion as well as on serum lipids and lipoproteins and to see if the effects, if any, were influenced by addition of long-chain n-3 fatty acids to the diet.

\section{Subjects and methods}

Design of the study. Five centres took part in the KANWU study as noted in the author affiliation list. The acronym KANWU refers to the location of the centres (Kuopio, Aarhus, Naples, Wollongong and Uppsala). This was a controlled study lasting 90 days in which the participants were chosen at random for a diet containing a high proportion of saturated fatty acids (SAFA diet) or monounsaturated fatty acids (MUFA diet). Within the groups there was a second random assignment to supplements of capsules containing fish oil (3.6 g n-3 fatty acids/day containing $2.4 \mathrm{~g}$ of eicosapentaenoic and docosahexaenoic fatty acids, i.e. three capsules twice daily of Pikasol, Lube A/S, Denmark) or placebo capsules containing the same amount of olive oil. The test period was preceded by a 2 -week "stabilisation period" on the habitual diets, when all subjects received placebo capsules. Routine clinical tests, including a $75 \mathrm{~g}$ oral glucose tolerance test [11] were carried out during this period and the participants kept a 3-day dietary record (two weekdays and one weekend day) to document pretrial dietary habits. Tests and laboratory analyses according to the study protocol were carried out during days -1 and 0 and repeated at days 89 and 90 at the end of the diet period. Two additional 3-day dietary records were done at the beginning of the second and third month of the treatment period.

Subjects. A total of 162 healthy men $(n=86)$ and women $(n=76)$ aged $30-65$ years with normal or moderately increased body weight (BMI $22-32 \mathrm{~kg} / \mathrm{m}^{2}$ ) were included (Table 1). In premenopausal women tests were all carried out during the same time period of the menstrual cycle. Subjects with impaired glucose tolerance were included but those with diabetes were excluded [11]. Health status was screened by medi-
Table 1. Clinical characteristics of the participants $($ mean \pm SD)

\begin{tabular}{lll}
\hline & SAFA $(n=83)$ & MUFA $(n=79)$ \\
\hline Age $($ years $)$ & $48.9 \pm 7.5$ & $48.2 \pm 8.1$ \\
BMI $\left(\mathrm{kg} / \mathrm{m}^{2}\right)$ & $26.6 \pm 2.9$ & $26.3 \pm 3.1$ \\
S-insulin (mU/l) & $7.15 \pm 4.19$ & $6.03 \pm 3.69$ \\
Insulin sensitivity index (Si) & $4.13 \pm 2.30$ & $4.76 \pm 3.25$ \\
B-glucose (mmol/l) & $5.19 \pm 0.44$ & $5.18 \pm 0.59$ \\
First-Phase Insulin Response & & \\
(mU/l) & $36.6 \pm 22.9$ & $37.8 \pm 29.2$ \\
S-cholesterol (mmol/l) & $5.40 \pm 0.85$ & $5.43 \pm 0.93$ \\
S-triglycerides (mmol/l) & $1.24 \pm 0.58$ & $1.14 \pm 0.62$ \\
S-LDL cholesterol (mmol/l) & $3.66 \pm 0.77$ & $3.66 \pm 0.86$ \\
S-HDL-cholesterol (mmol/l) & $1.24 \pm 0.37$ & $1.33 \pm 0.42$ \\
ApoB (g/l) & $0.99 \pm 0.20$ & $1.01 \pm 0.21$ \\
ApoA-I (g/l) & $1.40 \pm 0.28$ & $1.47 \pm 0.35$ \\
Lp(a) (U/l) & $206 \pm 201$ & $255 \pm 277$ \\
\hline S serum; P plasma; U &
\end{tabular}

$\mathrm{S}=$ serum; $\mathrm{P}=$ plasma; $\mathrm{U}=$ units .

cal history and routine laboratory examinations. The degree of physical activity and alcohol intake did not change throughout the study. Body weight changes in subjects were less than $4 \mathrm{~kg}$ during the 3 months preceding the study. Subjects using lipid lowering drugs, thiazide diuretics, beta blockers and corticosteroids were excluded. Moderate smokers were allowed to participate but they were instructed not to change their smoking habits during the trial.

All participants gave their informed consent to the study which was approved by the ethics committee at the medical faculties of the universities of Kuopio, Aarhus, Naples, Wollongong and Uppsala, respectively.

Diets. All participants were instructed to eat isoenergetic diets with the same proportions of the main nutrients, including similar amounts of total fat, but with a high proportion of saturated (SAFA diet) or monounsaturated (MUFA diet) fatty acids. The diets were calculated to contain 37 energy per cent $(\mathrm{E} \%)$ fat with $17 \mathrm{E} \%, 14 \mathrm{E} \%$ and $6 \mathrm{E} \%$ of saturated, monounsaturated and polyunsaturated atty acids, respectively, in the SAFA diet; and $8 \mathrm{E} \%, 23 \mathrm{E} \%$ and $6 \mathrm{E} \%$ in the MUFA diet. The estimated proportion of trans fatty acids was low and similar in both diets. All participants were instructed before the study by trained dietitians on the preparation of their diets. The participants met with dietitians at least every second week thereafter until the end of the study to assure good adherence to the diet. They were all supplied with edible fats to be used as spreads on bread, for cooking and in dressings. Core foods such as margarine, oils and a range of other staple items were provided. The subjects were not informed as to the type of diet they were following.

Butter, margarines and oils to be used in the diets were prepared centrally and distributed to the different European centres. The SAFA diet included butter and a table margarine containing a relatively high proportion of SAFAs. The MUFA diet included a spread and a margarine containing high proportions of oleic acid derived from high-oleic sunflower oil and negligable amounts of trans fatty acids and n-3 fatty acids and olive oil. The study centre in Australia obtained similar oils and margarines including high-oleic sunflower oil from local suppliers.

The intake during the test period was calculated as the mean values of the dietary records provided during the second 
and third month of the study. Local nutrient analysis software programs containing country-specific food databases were used in the analyses. Data on margarines and other specially prepared foods were entered onto these databases for inclusion in the analysis. Serum lipid fatty acid composition was measured to confirm the validity of reported dietary fattyacid intake.

Clinical tests and laboratory analyses. Blood samples were drawn after a 12-h overnight fast from an antecubital vein. The laboratory analyses were centralised to the research laboratory of one of the participating centres, with the exception of blood glucose and serum lipoprotein lipid concentrations which were measured locally on fresh samples. All other blood serum and plasma samples were kept frozen at $-70^{\circ} \mathrm{C}$ until transport and kept frozen during transport to the laboratory where they were analysed.

Intravenous glucose tolerance test (IVGTT) was done as described previously [12]. A glucose dose of $300 \mathrm{mg} / \mathrm{kg}$ body weight was given intravenously using a catheter followed by a bolus of $0.03 \mathrm{U} / \mathrm{kg}$ of insulin $20 \mathrm{~min}$ after the glucose. To measure plasma glucose and insulin concentrations, venous blood samples were collected before the glucose dose and 11 times after the glucose dose up to $180 \mathrm{~min}$ using a catheter in the contralateral arm. To arterialize the venous blood, the arm was kept in a $50^{\circ} \mathrm{C}$ electric pad during the test. The data were analysed by calculating the insulin sensitivity index $\left(\mathrm{S}_{\mathrm{I}}\right)$ with the Minmod program [13]. The first-phase insulin response was defined as the mean of the insulin concentrations at 2, 4 and $8 \mathrm{~min}$ minus the fasting insulin values. Serum insulin concentrations were measured by an enzyme-linked immunosorbent assay (ELISA) for specific determination of biologically active insulin (DAKO Insulin, Dako Diagnostics, Ely, UK) [14]. Plasma glucose concentration was analysed locally by a glucose oxidase method.

Enzymatic colorimetric methods were used to measure cholesterol and triglycerides in serum. Apolipoprotein B-containing lipoproteins were precipitated with a sodium phosphotungstate and magnesium chloride solution [15] or with dextran sulphate and magnesium chloride [16]. Low density lipoprotein cholesterol was calculated according to Friedewald et al. [17]. Analyses of apolipoprotein A-I and B were based on the measurement of immunoprecipitation enhanced by polyethylene glycol at $340 \mathrm{~nm}$. An automated Kone Specific Clinical Analyzer and apoA-I and apoB reagents from Kone Instruments (Espoo, Finland) were used in the analyses. The apolipoprotein(a) $[\operatorname{Apo}(a)]$ content in Lipoprotein(a) [Lp(a)] was measured using the solid-phase two-site immunoradiometric assay from Mercodia AB (Uppsala, Sweden). To transform the concentration of $\operatorname{Apo}(a)$ to $\operatorname{Lp}(\mathrm{a}) \operatorname{Apo}(\mathrm{a})$ concentrations were multiplied by 0.7 and the results are expressed in units per litre (U/l).

The fatty acids in the serum lipid esters were separated by gas-liquid chromatography as described earlier [18].

Statistical methods. Results for continuous variables are presented as mean and standard deviation. For variables with skewed distributions a logarithmic or a square root (insulin sensitivity) transformation was made before the statistical analysis. The main outcome variable in the statistical analysis was the change in insulin sensitivity. Secondary outcome variables were changes in insulin secretion and lipoprotein lipids.

For the intention-to-treat population (defined as all subjects assigned at random who had at least one measurement made during treatment) a confirmatory analysis was made. For each outcome variable the treatment effects were estimat- ed from a statistical model in which treatment categories (SAFA diet/MUFA diet and the presence/absence of n-3 fatty acid) and their interaction were analysed. Factors and treatment centre, age, sex and the baseline value of the outcome variable were covariates. For outcome variables where the interaction between the analysed factors and the presence or absence of n-3 fatty acid were non-significant a limited model was used excluding those terms [19]. Results of the analysis are presented as adjusted mean treatment effects within groups and their $p$-values. Furthermore the difference between treatment groups for adjusted mean treatment effects are presented with $p$-values and $95 \%$ confidence intervals. Confidence intervals are also presented on the original scale in the case of transformed variables.

Post-hoc analysis. A subgroup analysis was made according to relative intake of total fat during treatment (above or below median intake of $37.0 \%$ ). The above mentioned model was used with the addition of an interaction term between treatment and relative fat intake (above or below median).

\section{Results}

Clinical characteristics. Clinical characteristics of the subjects assigned at random to the SAFA diet and MUFA diet group were similar (Table 1).

Diet concordance. Dietary records. The average nutrient composition before the study, as calculated from the dietary records (Table 2), was similar in the group of subjects chosen at random for the SAFA diet and the MUFA diet. During the test period there was a slight increase in the proportion of dietary fat in both groups. The recorded mean intake of fat and fatty acids during the study was close to the target values.

Effects on the fatty acid composition of the serum lipid esters. The fatty acid changes of the serum phospholipids and the serum cholesterol esters reflected those of the dietary fat of the test diets. Thus, the changes of the proportions of the SAFAs with a chain length of 14 to 18 carbon atoms in the serum phospholipids (Table 3) and in the cholesterol esters (not shown) differed significantly during the two diets: concentrations increased or did not change on the SAFA diet and concentrations decreased or did not change on the MUFA diet. The proportion of 16:1 n-7 was significantly reduced on the MUFA diet with an increase of 18:1 n-9, which decreased on the SAFA diet. The proportions of the polyunsaturated $n-6$ fatty acids were similarly reduced on both diets while those of 20:5 n-3 and 22:6 n-3 increased during both diets as a consequence of the supplementation with n-3 fatty acids.

Effects on body weight. The mean body weight and body mass index (BMI) remained unchanged during the test period. The BMI (mean \pm SD) before and at 
Table 2. Dietary nutrient composition (all subjects, $n=162$ ) before and during the study

\begin{tabular}{|c|c|c|c|c|c|c|}
\hline & \multicolumn{2}{|l|}{ SAFA diet } & \multicolumn{2}{|l|}{ MUFA diet } & \multicolumn{2}{|c|}{$\begin{array}{l}\text { Target values for fat composition } \\
\text { during the study }\end{array}$} \\
\hline & Before & During & Before & During & SAFA & MUFA \\
\hline Protein (E \%) & $15.6 \pm 3.0$ & $15.2 \pm 2.5$ & $15.8 \pm 2.8$ & $14.8 \pm 2.3$ & & \\
\hline Carbohydrate (E \%) & $45.8 \pm 6.7$ & $44.1 \pm 5.2$ & $47.3 \pm 7.0$ & $45.9 \pm 4.2$ & & \\
\hline $\begin{array}{l}\text { Fat }(\mathrm{E} \%) \\
\text { SAFA (E \%) } \\
\text { MUFA (E \%) } \\
\text { PUFA (E \%) }\end{array}$ & $\begin{array}{r}33.7 \pm 6.5 \\
13.5 \pm 3.6 \\
13.0 \pm 3.7 \\
4.8 \pm 1.6\end{array}$ & $\begin{array}{r}37.1 \pm 4.1 \\
17.6 \pm 2.5 \\
13.1 \pm 2.5 \\
4.7 \pm 1.5\end{array}$ & $\begin{array}{r}33.3 \pm 6.1 \\
13.3 \pm 3.7 \\
13.1 \pm 3.2 \\
4.7 \pm 1.5\end{array}$ & $\begin{array}{r}37.1 \pm 4.2 \\
9.6 \pm 1.8 \\
21.2 \pm 4.0 \\
4.6 \pm 0.8\end{array}$ & $\begin{array}{r}37 \\
17 \\
14 \\
6\end{array}$ & $\begin{array}{r}37 \\
8 \\
23 \\
6\end{array}$ \\
\hline Fibre (g/day) & $23.8 \pm 7.7$ & $22.4 \pm 6.6$ & $23.0 \pm 8.4$ & $23.0 \pm 8.4$ & & \\
\hline Cholesterol (mg/day) & $316 \pm 126$ & $322 \pm 91$ & $310 \pm 139$ & $254 \pm 80$ & & \\
\hline
\end{tabular}

Table 3. Effects of treatment diets on serum phospholipid fatty acid composition (\%)

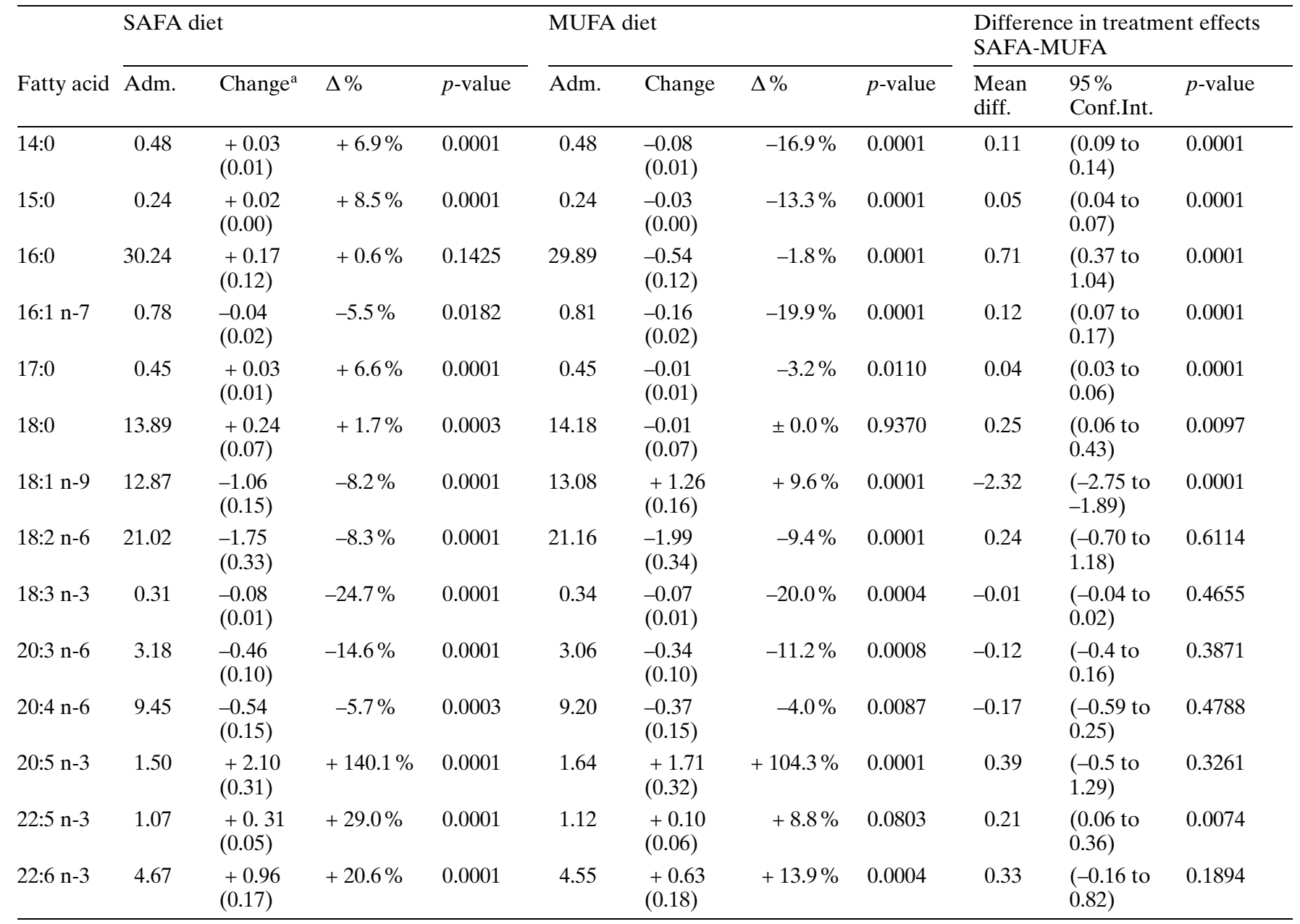

${ }^{a}$ Mean change during treatment expressed as least square mean (SE); Adm. = admission; $95 \%$ Conf. int. = 95\% confidence interval

the end of the SAFA diet period was $26.6 \pm 2.9$ and $26.7 \pm 2.9$, respectively and on the MUFA diet $26.3 \pm 3.1$ and $26.3 \pm 3.2 \mathrm{~kg} / \mathrm{m}^{2}$.

Effects on insulin sensitivity and insulin secretion. The insulin sensitivity index ( $\mathrm{Si}$ ) decreased significantly during the SAFA diet by $10 \%(p<0.05)$ but did not change during the MUFA diet (Table 4). The difference between the two treatments was of border line significance $(p=0.05)$. The serum fasting insulin concentrations were not changed on the SAFA diet but decreased slightly $(-5.8 \%, p<0.05)$ on the MUFA 
Table 4. Effects of treatment diets on insulin sensitivity, fasting insulin, peak insulin secretion and blood glucose concentrations

\begin{tabular}{|c|c|c|c|c|c|c|c|c|c|c|c|}
\hline & \multicolumn{4}{|c|}{ SAFA diet } & \multicolumn{4}{|c|}{ MUFA diet } & \multicolumn{3}{|c|}{$\begin{array}{l}\text { Difference in treatment effects } \\
\text { SAFA-MUFA }\end{array}$} \\
\hline & Adm. & Change $^{a}$ & $\Delta \%$ & $p$-value & Adm. & Change & $\Delta \%$ & $p$-value & $\begin{array}{l}\text { Mean } \\
\text { diff. }\end{array}$ & $\begin{array}{l}95 \% \\
\text { Conf. Int. }\end{array}$ & $p$-value \\
\hline $\begin{array}{l}\text { Serum insulin } \\
(\mathrm{mU} / \mathrm{l})\end{array}$ & 7.15 & $\begin{array}{l}+0.25 \\
(0.35)\end{array}$ & $+3.5 \%$ & 0.4662 & 6.03 & $\begin{array}{l}-0.35 \\
(0.36)\end{array}$ & $-5.8 \%$ & 0.0490 & 0.60 & $\begin{array}{l}(-0.40 \text { to } \\
1.60)\end{array}$ & 0.0582 \\
\hline $\begin{array}{l}\text { Plasma-glucose } \\
(\mathrm{mmol} / \mathrm{l})\end{array}$ & 5.19 & $\begin{array}{l}+0.00 \\
(0.04)\end{array}$ & $\pm 0.0 \%$ & 0.9950 & 5.18 & $\begin{array}{l}-0.03 \\
(0.04)\end{array}$ & $-0.6 \%$ & 0.4126 & 0.03 & $\begin{array}{l}(-0.07 \text { to } \\
0.14)\end{array}$ & 0.5572 \\
\hline
\end{tabular}

${ }^{a}$ Mean change during treatment expressed as least square mean (SE); Adm = admission; $95 \%$ Conf. Int. = 95\% confidence interval

Table 5. Effects of treatment diets on fasting serum lipid and apolipoprotein concentrations

\begin{tabular}{|c|c|c|c|c|c|c|c|c|c|c|c|}
\hline & \multicolumn{4}{|c|}{ SAFA diet } & \multicolumn{4}{|c|}{ MUFA diet } & \multicolumn{3}{|c|}{$\begin{array}{l}\text { Difference in treatmenteffects } \\
\text { SAFA-MUFA }\end{array}$} \\
\hline & Adm. & Change $^{\mathrm{a}}$ & $\Delta \%$ & $p$-value & Adm. & Change & $\Delta \%$ & $p$-value & $\begin{array}{l}\text { Mean } \\
\text { diff. }\end{array}$ & $\begin{array}{l}95 \% \\
\text { Conf.Int. }\end{array}$ & $p$-value \\
\hline $\begin{array}{l}\text { Cholesterol } \\
(\mathrm{mmol} / \mathrm{l})\end{array}$ & 5.40 & $\begin{array}{l}+0.14 \\
(0.06)\end{array}$ & $+2.5 \%$ & 0.0176 & 5.43 & $\begin{array}{l}-0.15 \\
(0.06)\end{array}$ & $-2.7 \%$ & 0.0122 & 0.28 & $\begin{array}{l}(0.12 \text { to } \\
0.45)\end{array}$ & 0.0007 \\
\hline $\begin{array}{l}\text { Triglycerides } \\
(\mathrm{mmol} / \mathrm{l})\end{array}$ & 1.24 & $\begin{array}{l}-0.11 \\
(0.06)\end{array}$ & $-9.1 \%$ & 0.0154 & 1.14 & $\begin{array}{l}-0.13 \\
(0.06)\end{array}$ & $-11.1 \%$ & 0.0009 & 0.01 & $\begin{array}{l}(-0.15 \text { to } \\
0.17)\end{array}$ & 0.4879 \\
\hline $\begin{array}{l}\text { HDL-Cholesterol } \\
(\mathrm{mmol} / \mathrm{l})\end{array}$ & 1.24 & $\begin{array}{l}+0.04 \\
(0.03)\end{array}$ & $+3.8 \%$ & 0.3646 & 1.33 & $\begin{array}{l}+0.04 \\
(0.03)\end{array}$ & $+3.4 \%$ & 0.1386 & -0.01 & $\begin{array}{l}(-0.08 \text { to } \\
0.07)\end{array}$ & 0.6708 \\
\hline ApoB (g/l) & 0.99 & $\begin{array}{l}+0.02 \\
(0.01)\end{array}$ & $+2.1 \%$ & 0.1071 & 0.95 & $\begin{array}{l}-0.04 \\
(0.01)\end{array}$ & $-4.3 \%$ & 0.0018 & 0.06 & $\begin{array}{l}(0.03 \text { to } \\
0.10)\end{array}$ & 0.0010 \\
\hline
\end{tabular}

${ }^{a}$ Mean change during treatment expressed as least square mean (SE); Adm = admission; $95 \%$ Conf. Int. = 95\% confidence interval

diet ( $p=0.06$ for group difference). The fasting concentration of plasma glucose and the first phase insulin secretion did not alter.

Addition of n-3 fatty acids did not influence insulin sensitivity or insulin secretion and there was no interaction between the treatment effect (the comparison between the effects of the SAFA and MUFA diets) and the effect of $n-3$ fatty acids. The insulin sensivity index before and after addition of $\mathrm{n}-3$ fatty acids was $4.4 \pm 3.1$ and $4.2 \pm 2.8$, respectively and in the placebo group $4.4 \pm 2.5$ and $4.4 \pm 2.5$.

Effects on serum lipid and lipoprotein concentrations. There were significantly different effects of the SAFA diet and the MUFA diet on the serum cholesterol and LDL cholesterol concentrations, the ApoB concentrations and on $\mathrm{Lp}(\mathrm{a})$ (Table 5). Serum cholesterol and LDL cholesterol increased by $2.5(p<0.05)$ and $4.1 \%(p<0.01)$, respectively, on the SAFA diet. They decreased on MUFA by $2.7(p<0.05)$ and $5.2 \%(p<0.001)$ with a significant reduction of ApoB on the latter diet. The differences between the two diets were all statistically significant. The $\mathrm{Lp}$ (a) did not alter on the SAFA diet but increased significantly on the MUFA diet by $12 \%(p<0.001)$. There were no interactions between the treatment effect and the effect of n-3 fatty acids on serum lipoprotein composition.

The n-3 fatty acid supplements showed a significant effect on LDL cholesterol, which was independent of the type of fat in the background diet. Those subjects who had n-3 fatty acids had higher LDL cholesterol concentrations than those who had placebo capsules. Thus, the increase of LDL cholesterol in the SAFA diet was due to an increase among the subjects who took the supplements with n-3 fatty acids 


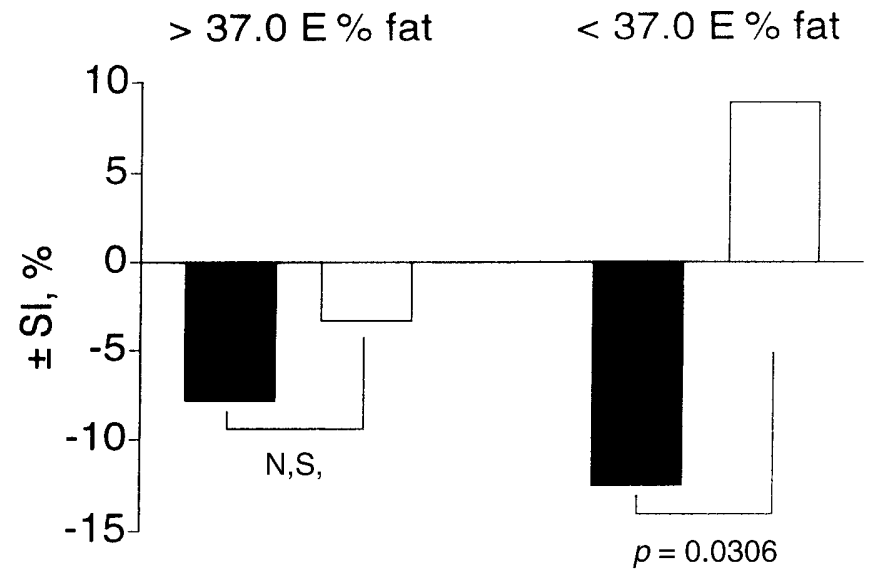

Fig. 1. Effects of a change of dietary fat quality on insulin sensitivity when related to total dietary fat intake during treatment

$(+7.8 \%, p<0.001)$. Those subjects, however, on placebo capsules had concentrations that did not change ( $+0.7 \%, \mathrm{NS})$. On the MUFA diet, a significant reduction of LDL cholesterol was seen only among the participants who took the placebo capsules $(-7.7 \%$, $p<0.001)$ while the mean LDL cholesterol concentrations remained virtually unchanged $(-2.7 \%, \mathrm{NS})$ after addition of n-3 fatty acids which counteracted the expected decrease of LDL cholesterol.

The reduction of serum triglycerides seen in both the SAFA diet and MUFA diet groups during treatment was entirely due to a significant reduction by about $20 \%$ among the participants who got supplements with n-3 fatty acids. There was no effect on the serum triglycerides when the proportions of saturated and monounsaturated fatty acids changed in the diet.

Effect of a change of dietary fat quality in relation to total fat intake. The median fat intake, as according to dietary records kept during the study period, was $37.0 \mathrm{E} \%$. If the data were analysed after exclusion of the $5 \%$ with the lowest (below $30 \mathrm{E} \%$ ) and highest (above $44 \mathrm{E} \%$ ) fat intake, the difference between treatments was $15.7 \%(p<0.02)$. When the effects of treatment were analysed in participants with a fat intake above and below median during the study, respectively, the diverging effect of dietary saturated and monounsaturated fatty acids on insulin sensitivity was seen mainly in subjects with a fat intake below median (mean intake 33.9E \%) (Fig.1). The mean changes of $\mathrm{Si}$ on the SAFA diet $(-12.5 \%)$ and MUFA $(+8.8 \%)$ diet were significantly different $(p=0.03)$. When the total fat intake was high (mean intake $40.2 \mathrm{E} \%$ ) there was no significant difference between the effects of the SAFA $(-7.8 \%)$ and MUFA $(-3.3 \%)$ diets on Si. The difference in the fat intake between the two groups was explained by a proportionally similar increase of both SAFA diet and MUFA diet in the group with a high fat intake.

\section{Discussion}

A number of dietary interventions have aimed to investigate the effect of dietary fat quality on insulin sensitivity [21-32]. Up to now there have been no controlled studies that had an adequate and validated methodology and showed the effects of a change of dietary fat quality on insulin sensitivity in humans. Our study shows that a shift from saturated to monounsaturated fatty acids in a controlled study, under isoenergetic conditions, improves insulin sensitivity in healthy humans. This underlines the importance of the choice of fat quality in the diet not only in relation to the lipid concentrations. Lowering fat intake to below $30 \%$ of energy, as currently recommended, is difficult [20]. The present results, however, show that even in the range where up to $37 \%$ of calorie intake is fat, changing the fat quality can effect changes in insulin action of greater than $20 \%$ along with a significant improvement in lipid profile. Such changes are feasible on a population basis and offer a genuine dietary approach to prevention and therapy of the metabolic syndrome.

The addition of n-3 fatty acids to the diet did not, independent of the fatty acid composition of the background diet, affect insulin sensitivity in this study. This is at variance with some rodent studies [3] but the literature on humans is controversial. Epidemiological studies have linked fish intake and protection against glucose intolerance [33, 34]. In contrast, most intervention studies have been negative [27-32]. The close relation between circulating triglyceride concentrations and insulin resistance has been shown many times. Therefore it is reasonable to assume that the hypotriglyceridemic effect of n-3 fatty acids improves insulin action. It could, however, take years rather than months for the effects, if any, of n-3 fatty acids on insulin action to become apparent. Furthermore, it has been suggested that the n-6:n-3 ratio of skeletal muscle cell membranes might be important in determining insulin sensitivity [35]. It is possibble that an addition of n-3 fatty acids affects insulin sensitivity in people with very low initial concentrations of n-3 fatty acids or low ratios between n-3 and n-6 fatty acids, in target organs. In addition, it is possible that the effect of $n-3$ fatty acids on insulin sensitivity in healthy subjects could vary depending on the status of carbohydrate intolerance [36, 37]. The restricted number of subjects with glucose intolerance in the present study did not, however, permit a separate analysis comparing subjects with impaired and normal glucose tolerance.

Insulin secretion was not affected by a change of dietary fatty acid composition. This is in line with the findings from earlier controlled intervention studies in humans [10], although experimental data [7, 8] and meal studies in humans [9] have suggested that insulin secretion could also be differentially influenced by individual fatty acids. 
The LDL cholesterol concentration was on average about $9 \%$ higher for the SAFA diet than the MUFA diet. The major part of the LDL effect is probably due to the change of fatty acid composition but the slightly higher cholesterol content of the SAFA diet, due to the cholesterol content in the butter, could contribute marginally to the result. The reduction of serum triglycerides and increase of LDL cholesterol by $\mathrm{n}-3$ fatty acids has been well documented and the changes observed are close to what would be expected in normotriglyceridaemic subjects [38]. In addition, this study shows that similar changes of the triglyceride and LDL cholesterol concentrations are seen after supplementation with n-3 fatty acids, whether the diet is rich in saturated or unsaturated fatty acids.

The diverging effects of SAFA and MUFA on $\mathrm{Lp}(\mathrm{a})$ is in line with earlier findings showing increased $L p(a)$ concentrations when saturated fatty acids were replaced by oleic acid [39]. High proportions of trans fatty acids in the diet are known to increase $\operatorname{Lp}(\mathrm{a})[39,40]$ but this probably does not explain the present results, since the amount of trans fatty acids was similar in both diets.

The beneficial effect of the MUFA diet on insulin sensitivity was not seen when the fat intake was high. On the other hand a change in the proportion of fatty acids, reducing SAFA diet and increasing MUFA, induced a significant improvement in insulin sensitivity in subjects with lower fat intake. Thus, the influence of dietary fat quality is not solely due to an effect of the proportion of saturated fatty acids in the diet. In the present study there was no significant relation between the changes of the proportion or the total amount of SAFA alone and the changes of the insulin sensitivity index, within the groups or as a whole. At a high total-fat intake, the positive effects of MUFA contra SAFA seem to be lost with regard to insulin sensitivity, even if the proportion or total intake of SAFA is low. This finding is a strong argument for present nutrition recommendations underlining the importance not only of the fatty acid composition, but also the proportion of total fat in a diet.

Acknowledgements. Food for the study was generously supplied by MD Foods, Denmark; Carlshamns mejeri AB, Svenska Nestlé AB and Van den Bergh Foods AB, Sweden; Eridania and Beghin-Say, Belgium and Meadow Lea Foods, Australia. The Pikasol capsules were supplied by Lube A/S, Denmark. The study was supported by the Swedish Council for Forestry and Agricultural Research, Health Research Council Academy of Finland, The Danish Medical Research Council, Helga and Peter Kornings Foundation and International Council of Olive oil.

\section{References}

1. DeFronzo RA, Ferrannini E (1991) Insulin resistance: a multifaceted syndrome responsible for NIDDM, obesity, hypertension, dyslipidemia and atherosclerotic cardiovascular disease. Diabetes Care 14: 173-194

2. Seidell JS (2000) Obesity, insulin resistance and diabetes a world wide epidemic? Br J Nutr 83 [Suppl 1]: S5-S8

3. Storlien LH, Baur LA, Kriketos AD et al. (1996) Dietary fats and insulin action. Diabetologia 39: 621-631

4. Borkman M, Storlien LH, Pan DA, Jenkins AB, Chisholm DJ, Campbell LB (1993) The relationship between insulin sensitivity and the fatty acid composition of skeletal-muscle phospholipids. N Engl J Med 328: 238-244

5. Vessby B, Tengblad S, Lithell H (1994) The insulin sensitivity is related to the fatty acids of the serum lipids and of the skeletal muscle phospholipids in 70 year old men. Diabetologia 37: 1044-1050

6. Pan DA, Lillioja S, Milner MR et al. (1995) Skeletal muscle membrane lipid composition is related to adiposity and insulin action. J Clin Invest 96: 2802-2808

7. Stein DT, Stevenson BE, Chester MW et al. (1997) The insulinotropic potency of fatty acids is influenced profoundly by their chain length and degree of saturation. J Clin Invest 100: 398-403

8. Alstrup KK, Gregersen S, Jensen HM, Thomsen JL, Hermansen K (1999) Differential effects of cis and trans fatty acids on insulin release from isolated mouse islets. Metabolism 48: 22-29

9. Joannic J-L, Auboiron S, Raison J, Basdevant A, Bornet F, Guy-Grand B (1997) How the degree of unsaturation of dietary fatty acids influences the glucose and insulin responses to different carbohydrates in mixed meals. Am J Clin Nutr 65: 1427-1433

10. Vessby B (2000) Dietary fat and insulin action in humans. Br J Nutr 83 [Suppl 1]: S91-S96

11. World Health Organization Expert Committee on Diabetes mellitus (1985) Technical report series no 742, WHO, Geneva

12. Steil GM, Volund A, Kahn SE, Bergman RN (1993) Reduced sample number for calculation of insulin sensitivity and glucose effectiveness from the minimal model. Suitability for use in population studies. Diabetes 42: 250-256

13. Pacini G, Bergman RN (1986) A computer program to calculate insulin sensitivity and pancreatic responsitivity from the frequently sampled intravenous glucose tolerance test. Comput Methods Programs Biomed 23: 112-122

14. Andersen L, Dinesen B, Jörgensen PN, Poulsen F, Röder ME (1993) Enzyme immunoassay for intact human insulin in serum or plasma. Clin Chem 39: 578-582

15. Seigler L, Wu WT (1981) Separation of serum high density lipoprotein for cholesterol determination: ultracentrifugation vs precipitation with sodium phosphotungstate and magnesium chloride. Clin Chem 27: 838-841

16. Penttilä IM, Voutilainen E, Laitinen $O$, Juutilainen $P$ (1981) Comparison of different analytical and precipitation methods for the direct estimation of high-density lipoprotein cholesterol. Scand J Clin Lab Invest 41: 353-360

17. Friedewald W, Levy R, Fredrickson D (1972) Estimation of the concentration of low-density lipoprotein cholesterol in plasma, without use of preparative ultracentrifuge. Clin Chem 18: 499-502

18. Boberg M, Croon L-B, Gustafsson IB, Vessby B (1985) Platelet fatty acid composition in relation to fatty acid composition in plasma and to serum lipoprotein lipids in healthy subjects with special reference to the linoleic acid pathway. Clin Sci (Colch) 68: 581-587 
19. Edwards D (1999) On model prespecification in confirmatory randomized studies. Stat Med 18: 771-785

20. Toeller M, Klischan A, Heitkamp G et al. (1996) Nutritional intake of 2868 IDDM patients from 30 centres in Europe. Diabetologia 39: 929-939

21. Uusitupa M, Schwab U, Mäkimattila S et al. (1994) Effects of two high fat diets with different fatty acid composition on glucose and lipid metabolism in healthy young women. Am J Clin Nutr 59: 1310-1316

22. Schwab US, Niskanen LK, Maliranta HM, Savolainen MJ, Kesaniemi YA, Uusitupa MI (1995) Lauric and palmitic acid-enriched diets have minimal impact on serum lipid and lipoprotein concentrations and glucose metabolism in healthy young women. J Nutr 125: 466-473

23. Fasching P, Ratheiser K, Schneeweiss B, Rohac M, Nowotny P, Waldhausl W (1996) No effect of short term dietary supplementation of saturated and poly- and MUFAs on insulin secretion and sensitivity in healthy men. Ann Nutr Metab 40: 116-122

24. Louheranta AM, Turpeinen AK, Schwab US, Vidgren HM, Parviainen MT, Uusitupa MI (1998) A high stearic acid diet does not impair glucose tolerance and insulin sensitivity in healthy women. Metabolism 47: 529-534

25. Louheranta AM, Turpeinen AK, Vidgren HM, Schwab US, Uusitupa MI (1999) A high-trans fatty acid diet and insulin sensitivity in young healthy women. Metabolism 48: 870-875

26. Toft I, Bönaa K, Ingebretsen OC, Nordoy A, Jenssen T (1995) Effects of n-3 polyunsaturated fatty acids on glucose homeostasis and blood pressure in essential hypertension. A randomized, controlled trial. Ann Intern Med 123: 911-918

27. Borkman M, Chisholm DJ, Furler SM et al. (1989) Effects of fish-oil supplementation on glucose and lipid metabolism in NIDDM. Diabetes 38: 1314-1319

28. Annuzzi G, Rivellese A, Capaldo B, Marino L, Marotta G, Riccardi G (1991) A controlled study on the effects of n-3 fatty acids on lipid and glucose metabolism in non-insulin dependent diabetic patients. Atherosclerosis 87: 65-73

29. Boberg M, Pollare T, Siegbahn A, Vessby B (1992) Supplementation with n-3 fatty acids reduces triglycerides but increases PAI-1 in non-insulin-dependent diabetes mellitus. Eur J Clin Invest 22: 645-650
30. McManus RM, Jumpson J, Finegood DT, Clandinin MT, Ryan EA (1996) A comparison of the effects of n-3 fatty acids from linseed oil and fish oil in well controlled type II diabetes. Diabetes Care 19: 463-476

31. Rivellese AA, Maffettone A, Iovine C et al. (1996) Longterm effects of fish oil on insulin resistance and plasma lipoproteins in NIDDM patients with hypertriglyceridemia. Diabetes Care 19: 1207-1213

32. Lou J, Rizkalla SW, Vidal H et al. (1998) Moderate intake of n-3 fatty acids for 2 months has no detrimental effect on glucose metabolism and could ameliorate the lipid profile in Type II diabetic men. Results of a controlled study. Diabetes Care 21: 717-724

33. Feskens EJM, Bowles C, Kromhout D (1991) Inverse association between fish intake and risk of glucose intolerance in normoglycemic elderly men and women. Diabetes Care 14: 935-941

34. Adler AI, Boyko EJ, Schrarer CD, Murphy NJ (1994) Lower prevalence of impaired glucose tolerance and diabetes associated with daily seal oil or salmon consumption among Alaska natives. Diabetes Care 17: 1498-1501

35. Storlien LH, Pan DA, Kriketos AD et al. (1996) Skeletal muscle membrane lipids and insulin resistance. Lipids 31: S261-S265

36. Waldhäusl W, Ratheiser K, Komjati M, Nowotny P, Pirich K, Vierhapper H. (1989) Increase of insulin sensitivity and intravenous glucose tolerance by fish oil in healthy man. In: RK Chandra (ed), "Health Effects of Fish and Fish Oils". ARTS Biomedical Publishers \& Distributors, St John's, Newfoundland, p 171-187

37. Fasching P, Ratheiser K, Waldhäusl W et al. (1991) Metabolic effects of fish-oil supplementation in patients with impaired glucose tolerance. Diabetes 40: 583-589

38. Harris WS (1997) N-3 fatty acids and serum lipoproteins: human studies. Am J Clin Nutr 65: S1645-S1654

39. Mensink RP, Zock PL, Katan MB, Hornstra G (1992) Effect of dietary cis and trans-fatty acids on serum lipoprotein(a) levels in humans. J Lipid Res 33: 1493-1591

40. Vessby B (1996) Diet and lipoprotein(a). Nutr Metab Cardiovasc Dis 6: 239-244 